\title{
Involvement of Non-NMDA Glutamate Receptors in Central Amygdala in Synaptic Actions of Ethanol and Ethanol-Induced Reward Behavior
}

\author{
Wei Zhu, Bihua Bie, and Zhizhong Z. Pan \\ Department of Anesthesiology and Pain Medicine, The University of Texas-MD Anderson Cancer Center, Houston, Texas 77030
}

\begin{abstract}
The central nucleus of the amygdala $(\mathrm{CeA})$ plays a critical role in positive emotional responses that involve stimulus-reward learning and are induced by the reinforcing effects of many drugs of abuse, including alcohol. Behavioral studies have implicated CeA as a key brain structure in alcohol reward, but the underlying mechanisms are still poorly understood. Recent studies have demonstrated that both NMDA and non-NMDA receptors in CeA neurons are targets of acute and chronic alcohol in naive and alcohol-dependent animals. However, little is known about the role of CeA non-NMDA receptors in synaptic actions of alcohol and, particularly, in the behavior of alcohol reward. In the present study with both whole-cell voltage-clamp recordings in CeA slices in vitro and analysis of an animal model of conditioned place preference (CPP) in vivo, we investigated the synaptic mechanisms for actions of acute and chronic ethanol on CeA non-NMDA receptor functions and their contribution to ethanol-induced reward behavior. Acute ethanol significantly inhibited evoked and miniature synaptic currents mediated by non-NMDA receptors through inhibitions of both postsynaptic non-NMDA receptors and presynaptic glutamate release involving $\mathrm{N}$-type $\mathrm{Ca}^{2+}$ channels. CeA neurons from rats exhibiting the ethanol-induced $\mathrm{CPP}$ behavior showed a significant increase in non-NMDA synaptic transmission. Blockade of this increased synaptic transmission through CeA microinjection abolished the CPP behavior. These results suggest that acute alcohol inhibits CeA non-NMDA synaptic transmission through both presynaptic and postsynaptic mechanisms, and chronic alcohol upregulates this synaptic activity, which is required for the alcohol-induced reward behavior.
\end{abstract}

Key words: alcohol addiction; EPSCs; AMPA receptors; whole-cell recording; conditioned place preference; drug abuse

\section{Introduction}

Alcoholism is a widespread behavioral disorder with excessive consumption of alcohol, resulting in alcohol dependence with aversive symptoms upon alcohol withdrawal (Tabakoff and Hoffman, 1996). Recent studies have shown that the amygdala complex is important for mediating reinforcing effects of many drugs of abuse, including alcohol (Koob et al., 1998; Baxter and Murray, 2002; Gottfried et al., 2003; See et al., 2003), and that the central nucleus of the amygdala (CeA) is critical for compulsive behavior of alcohol consumption (Koob, 2004).

Central glutamate synapses are critical in the acute actions of many abused drugs and in the neuroadaptive responses to longterm exposure to those drugs (Trujillo and Akil, 1991; Koob et al., 1998; Nestler, 2001). The glutamate synaptic system is also crucially implicated in the cellular and behavioral actions of acute alcohol and in neuroadaptive alterations in alcohol addiction (Krystal et al., 2003; Siggins et al., 2003). Most studies of alcohol

\footnotetext{
Received July 3, 2006; revised Dec. 5, 2006; accepted Dec. 5, 2006.

This work was supported by National Institute on Drug Abuse Grant DA014524 and by an institutional fund from University of Texas-MD Anderson Cancer Center.

Correspondence should be addressed to Dr. Zhizhong Z. Pan, Department of Anesthesiology and Pain Medicine, The University of Texas-MD Anderson Cancer Center, 1515 Holcombe Boulevard, Unit 110, Houston, TX 77030. E-mail:zzpan@mdanderson.org.

DOI:10.1523/JNEUROSCI.3912-06.2007

Copyright $\odot 2007$ Society for Neuroscience $\quad$ 0270-6474/07/270289-10\$15.00/0
}

actions focus on alcohol inhibition of the NMDA receptors (NMDARs) because of the initial discovery and subsequent demonstration of its high sensitivity to ethanol in many brain regions (Lovinger et al., 1989; Masood et al., 1994; Calton et al., 1998; Woodward, 2000; Criswell et al., 2003; Roberto et al., 2004; Siggins et al., 2005). Chronic ethanol causes a neuroadaptive increase in the function of NMDAR (Fadda and Rossetti, 1998). Despite the critical role of the glutamate synaptic system in drug addiction and important function of the $\mathrm{CeA}$ in compulsive behaviors of alcohol reward, only recently have a few studies emerged examining actions of acute and chronic alcohol on glutamate neurotransmission in CeA neurons. For example, Roberto et al. $(2004,2005)$ have shown that acute ethanol inhibits both NMDAR- and non-NMDAR-mediated EPSCs, and chronic ethanol enhances NMDAR sensitivity to ethanol at both presynaptic and postsynaptic sites and increases glutamate content in the CeA.

AMPA glutamate receptors (AMPARs) play a key role in activity-dependent synaptic plasticity that may underlie drug addiction (Hayashi et al., 2000; Ungless et al., 2001). In contrast to NMDAR, AMPAR in many brain sites examined is not affected by acute ethanol (Lovinger et al., 1989; Morrisett and Swartzwelder, 1993; Nie et al., 1994; Mameli et al., 2005). Interestingly, it has been reported recently that ethanol reduces nonNMDA EPSCs in CeA neurons (Roberto et al., 2004) and inhibits 
kainate receptors in hippocampal neurons (Weiner et al., 1999; Carta et al., 2003). However, details regarding synaptic sites and mechanisms of the ethanol actions on non-NMDAR-mediated synaptic transmission in CeA neurons are unclear at present. More importantly, despite extensive knowledge of alcohol actions on the glutamate receptor system in central neurons, including those in the CeA, the behavioral significance of those alcohol actions in alcohol reward and addiction has yet to be demonstrated.

Therefore, in the present study, we investigated synaptic mechanisms for ethanol inhibition of non-NMDAR as well as NMDAR in CeA neurons in vitro and the behavioral function of CeA non-NMDAR and NMDAR in ethanol-induced reward behavior in vivo.

\section{Materials and Methods}

All procedures involving the use of animals conformed to the guidelines set by the University of Texas-MD Anderson Cancer Center Animal Care and Use Committee.

Brain slice preparations. Male Wistar rats (150-200 g) were used for whole-cell recordings in brain slice preparations in vitro. A rat was anesthetized with inhalation of halothane and then killed by decapitation. The brain was removed and cut in a vibratome in cold $\left(4^{\circ} \mathrm{C}\right)$ physiological saline to obtain coronal slices (200-300 $\mu \mathrm{m}$ thick) containing the CeA. A single slice was submerged in a shallow recording chamber and perfused with preheated $\left(35^{\circ} \mathrm{C}\right)$ physiological saline (in mM: $126 \mathrm{NaCl}$, $2.5 \mathrm{KCl}, 1.2 \mathrm{NaH}_{2} \mathrm{PO}_{4}, 1.2 \mathrm{MgCl}_{2}, 2.4 \mathrm{CaCl}_{2}, 11$ glucose, $25 \mathrm{NaHCO}_{3}$ ), saturated with $95 \% \mathrm{O}_{2}$ and $5 \% \mathrm{CO}_{2}, \mathrm{pH} 7.2-7.4$. Slices were maintained at around $35^{\circ} \mathrm{C}$ throughout a recording experiment. Typically, one slice from a single rat was used each day.

Whole-cell recording. Visualized whole-cell voltage-clamp recordings were obtained from neurons in the medial division of the CeA in a slice. Neurons were visualized on a video monitor with a microscope with infrared illumination (Olympus America, Melville, NY). Whole-cell recordings were made with a glass pipette (resistance 3-5 M 2 ) filled with a solution containing the following (in $\mathrm{mM}$ ): 126 potassium gluconate, 10 $\mathrm{NaCl}, 1 \mathrm{MgCl}_{2}, 11$ EGTA, 10 HEPES, 2 ATP, $0.25 \mathrm{GTP}$, pH adjusted to 7.3 with $\mathrm{KOH}$ (osmolarity $280-290 \mathrm{mOsm} / \mathrm{L}$ ). An AxoPatch 1-D amplifier and AxoGraph software (Molecular Devices, Union City, CA) were used for data acquisition and on-line/off-line data analyses. Holding potential was generally $-70 \mathrm{mV}$. A seal resistance of $2 \mathrm{G} \Omega$ or above and an access resistance of $15 \mathrm{M} \Omega$ or less were considered acceptable. Series resistance was optimally compensated. The access resistance was monitored throughout the experiment. Junction potential was not corrected.

Electrical stimuli of constant current $(0.25 \mathrm{~ms}, 0.04-0.5 \mathrm{~mA})$ were used to evoke glutamate-mediated EPSCs with bipolar stimulating electrodes (FHC, Bowdoinham, ME) placed in the ventrolateral part of the CeA. The dependence of ethanol inhibition of non-NMDAR-mediated EPSCs on stimulus strength was studied with three stimulus intensities: intensity 3 (maximum) to elicit a maximum EPSC, intensity 2 at twothirds of the maximum intensity and intensity 1 at one-third of the maximum intensity. Other EPSCs were recorded with half of the maximum stimulus intensity. All EPSCs were recorded in the presence of $\mathrm{GABA}_{\mathrm{A}}$ receptor antagonist bicuculline $(30 \mu \mathrm{M})$. Non-NMDARmediated EPSCs were recorded in bicuculline plus the NMDAR antagonist AP5 $(30 \mu \mathrm{M})$. For recording of NMDAR-mediated EPSCs, a CsClfilled pipette was used with a holding potential of $+40 \mathrm{mV}$ in the presence of bicuculline and the non-NMDAR antagonist CNQX $(10 \mu \mathrm{M})$ (Zhu and Pan, 2004).

A pair of EPSCs was evoked by two stimuli with an interval of $40 \mathrm{~ms}$ for non-NMDA EPSCs and $150 \mathrm{~ms}$ for NMDA EPSCs. Paired-pulse ratio (PPR) was calculated by dividing the second EPSC amplitude by the first one. Six PPRs were averaged to obtain a mean PPR before and during application of a drug in a given cell. The PPR has been widely used to determine the involvement of a presynaptic action site (Dobrunz and Stevens, 1997; Ungless et al., 2001; Bie et al., 2005; Zhu and Pan, 2005). The PPR has an inverse relationship with the probability of presynaptic transmitter release so that an increased PPR indicates a reduced transmitter release, and vice versa. Miniature EPSCs (mEPSCs) were obtained in $60 \mathrm{~s}$ epochs in the presence of tetrodotoxin (TTX, $1 \mu \mathrm{M}$ ). The AxoGraph 4.7 was used to detect and measure the amplitude and interval of the miniature synaptic events and analyze their distribution data.

Recordings in slices from ethanol- (and saline-) conditioned rats were made in an ethanol-free solution $2-4 \mathrm{~h}$ after making the slice preparation, corresponding to a period of hyperactive behavioral state of early alcohol withdrawal (Roberto et al., 2004). One cell was usually recorded in a single slice, and occasionally, a second cell in the same slice was recorded if no ethanol treatment was involved and a previous drug effect was completely washed out. Drugs were applied through the bath solution. To avoid loss of ethanol by evaporation, ethanol solutions were diluted in gassed physiological saline from a sealed stock solution of reagent grade $95.0 \%$ ethyl alcohol immediately before administration.

Conditioned place preference. The conditioned place preference (CPP) paradigm has been widely used to measure the reward effect of many drugs of abuse, including alcohol (Tzschentke, 1998). A standard rat CPP apparatus (Med Associates, St. Albans, VT) was used for analysis of ethanol-induced reward behavior in rats. The CPP apparatus has two test chambers with distinct environmental cues: a black chamber with stainless steel rod grid floor and a white chamber with stainless steel mesh floor. A third center compartment in neutral gray connects the two test chambers with operational doors. Automated data were collected by 15 infrared photobeam detectors on chamber floors and were automatically sent to a computer for storage and analysis. The protocol for ethanolinduced CPP behavior in this study was adopted from previous studies of ethanol-induced CPP in rats (Bozarth, 1990; Bienkowski et al., 1996; Biala and Kotlinska, 1999; Matsuzawa et al., 1999) and in mice (Cunningham et al., 1998, 2003).

The conditioning procedure consisted of four phases and lasted for a total of 18 consecutive days. Phase 1, habituation (days 1-2): after an intraperitoneal saline injection, a rat was placed in the center compartment and allowed to move freely between the two test chambers for 30 min each day. Phase 2, pre-test (day 3): after a saline injection, the rat was placed in the center compartment, and a preference test was conducted by recording the time the rat spent in each of the two test chambers during a $30 \mathrm{~min}$ test period. This pre-test determined baseline preferences, i.e., whether the rat spent significantly more time in one chamber (preferred) than in the other (nonpreferred), regarded as equipment bias. Phase 3, ethanol conditioning (days 4-17): rats were randomly assigned to saline and ethanol groups; on day 4, the rat in the ethanol group was injected with ethanol ( $0.5 \mathrm{~g} / \mathrm{kg}, 10 \% \mathrm{w} / \mathrm{v}$, i.p.) and was immediately confined in a chamber for $20 \mathrm{~min}$. Ethanol conditioning was mostly paired with the nonpreferred chamber to prevent potential influence of a ceiling effect in CPP tests with equipment bias (Cunningham et al., 2003). On day 5 , the rat was injected with saline and confined in the other chamber for $20 \mathrm{~min}$. The same procedure of ethanol and saline conditioning on alternate days was repeated on days 6 and 7 through days 16 and 17. In the saline control group, rats received saline injection on all 14 conditioning days. Phase 4, post-test (day 18): after a saline injection, the conditioned rat was placed in the center compartment and allowed to move freely between the two test chambers for $30 \mathrm{~min}$. The time the rat spent in each test chamber was automatically recorded.

Blood alcohol level was determined in a separate group of rats $(n=10)$ after the same ethanol-conditioning procedure. Blood samples were taken from these rats at an approximate time (day 18) when a post-test would be conducted in other rat groups $(\sim 48 \mathrm{~h}$ after the last ethanol administration). No significant amount of ethanol was detected in any of the 10 blood samples $(<5 \mathrm{mg} / \mathrm{dl})$.

Cannula implantation and microinjection. General methods for sitespecific microinjection were similar to those used in our previous study (Ma and Pan, 2006). Before conditioning treatment, a rat was initially anesthetized with Nembutal sodium solution $(50 \mathrm{mg} / \mathrm{kg})$ and then maintained lightly anesthetized in a stereotaxic apparatus with a constant intravenous infusion of methohexital $(10 \mathrm{mg} / \mathrm{ml}$ at $0.8 \mathrm{ml} / \mathrm{hr})$. A 26 gauge single-guide cannula was inserted on each side of the brain, aiming at the CeA (anteroposterior, $-2.3 \mathrm{~mm}$ from the bregma; lateral, \pm 4.0 $\mathrm{mm}$; ventral, $-8.0 \mathrm{~mm}$ from dura) (Paxinos and Watson, 1986). The 

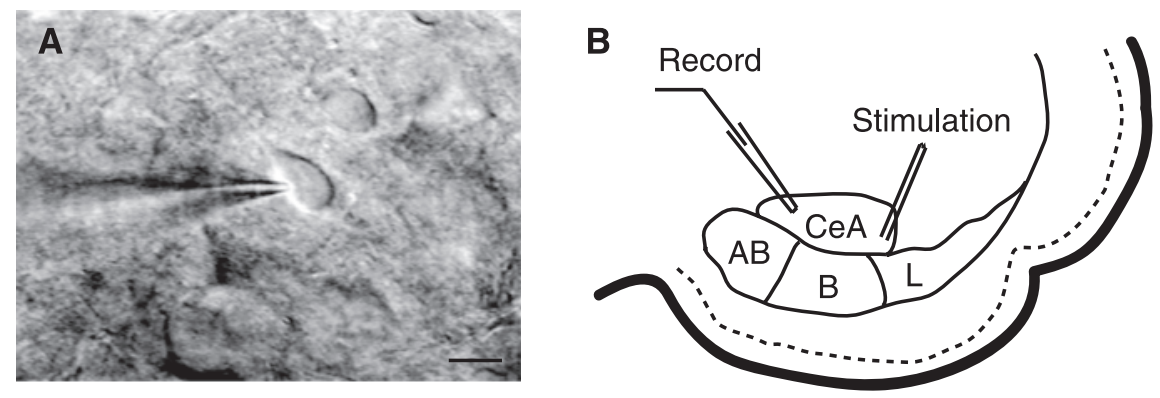

C

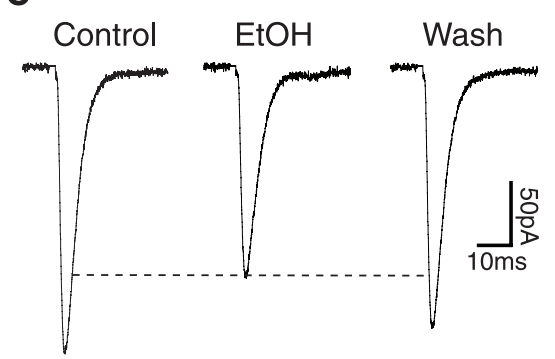

E

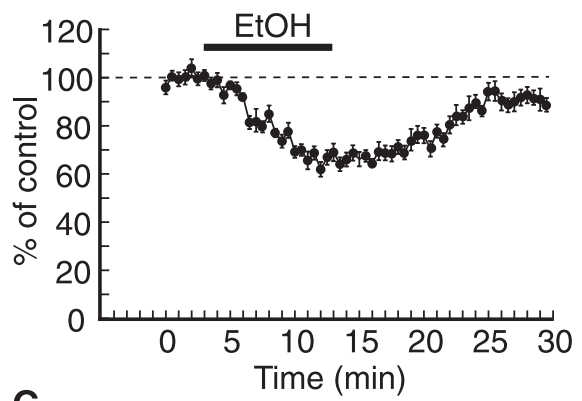

G

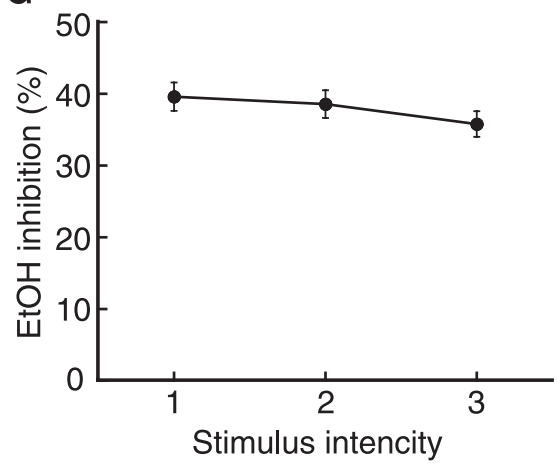

D

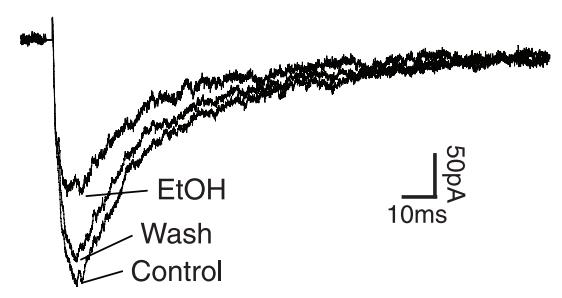

$\mathbf{F}$

H

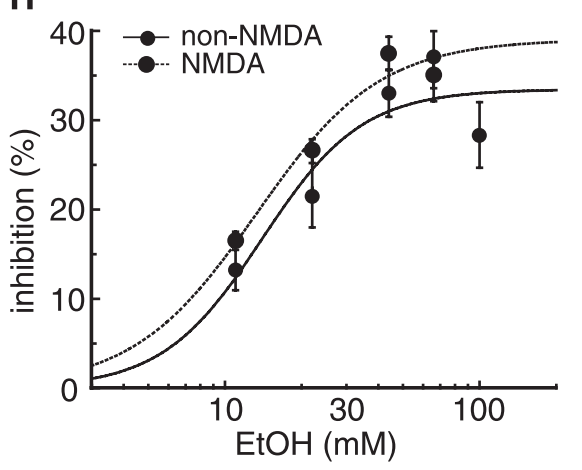

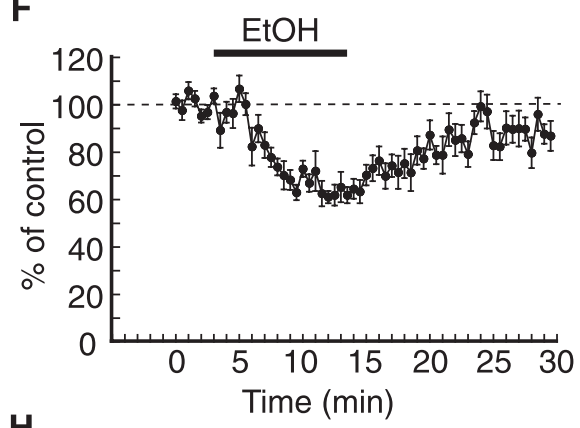

Figure 1. Ethanol inhibits both non-NMDAR- and NMDAR-mediated EPSCs in CeA neurons. $\boldsymbol{A}$, A photomicrograph showing a CeA neuron under whole-cell recording configuration in a CeA slice. Scale bar, $20 \mu \mathrm{m}$. $\boldsymbol{B}, \mathrm{A}$ diagram of a CeA slice depicting

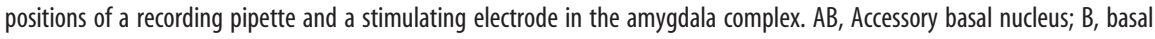
nucleus; L, lateral nucleus. $\boldsymbol{C}, \boldsymbol{D}$, Representative non-NMDA ( $\boldsymbol{C}$ ) and NMDA (D) EPSCs in control, in the presence of ethanol (EtOH; $44 \mathrm{~mm}$ ) and after washout of ethanol. All EPSCS were recorded in bicuculline (30 $\mu \mathrm{m})$. $\boldsymbol{E}, \boldsymbol{F}$, Time courses of ethanol inhibition on non-NMDA $(\boldsymbol{E} ; n=11)$ and NMDA $(\boldsymbol{F} ; n=8)$ EPSCs in CeA neurons. $\boldsymbol{G}$, Ethanol inhibition of non-NMDA EPSC $s$ at three stimulus intensities: maximum (3), two-thirds maximum (2) and one-third maximum (1). $\boldsymbol{H}$, Dose-response curves of ethanol inhibition of non-NMDA and NMDA EPSCs. The half-maximal concentration of ethanol was 13.3 mм for NMDA EPSCs and 14.0 mm for nonNMDA EPSCs. Error bars represent SEM.

guide cannula was then cemented in place to the skull and capped. After the implantation surgery, the rat was allowed to recover for 1 week before undergoing the conditioning procedure. CeA microinjection was performed on day 19 after ethanol conditioning and demonstration of the ethanol-induced CPP behavior in a post-test. Drugs were delivered into the CeA through a 33-gauge single injector cannula with an infusion pump at a rate of $0.1 \mu \mathrm{l} / \mathrm{min}$. A total of $0.5 \mu \mathrm{l}$ was injected on each side.
All cannula placements for bilateral CeA were histologically verified afterward.

Data analysis and statistical tests. General numerical data were statistically tested with a paired or unpaired Student's $t$ test and presented as mean \pm SEM. Data of mEPSCs were tested by StatView software (SAS Institute, Cary, NC) with the Kolmogorov-Smirnov test. CPP data were presented in two forms as described previously (Cunningham et al., 2003): (1) actual time in seconds that a rat spent in the ethanol-paired chamber during a $30 \mathrm{~min}$ test period (pre-test, post-test, and postmicroinjection test); and (2) percentage of time that a rat spent in the ethanol-paired chamber over the sum $(100 \%)$ of the times spent in both of the two test chambers during a $30 \mathrm{~min}$ test period (excluding the time spent in the center compartment). CPP behavior was determined by comparing times (in seconds or percentage term) spent in the ethanol-paired chamber between pre-test and post-test in ethanolconditioned rats and between ethanolconditioned and saline-conditioned rat groups in post-tests. Two-factor ANOVA was used to statistically analyze CPP data both in seconds and in percentage term. $p<0.05$ was considered statistically significant.

Materials. All drugs were purchased from Tocris Bioscience (Ellisville, MO) or from Sigma-Aldrich (St. Louis, MO).

\section{Results}

Ethanol inhibits non-NMDAR- and

NMDAR-mediated EPSCs

Whole-cell voltage-clamp recordings were obtained from neurons mostly in the medial division of the CeA (Fig. $1 A, B$ ). The majority of these neurons were fusiform or bipolar in morphology. Both NonNMDAR- and NMDAR-mediated EPSCs were recorded in the presence of $\mathrm{GABA}_{\mathrm{A}}$ receptor antagonist bicuculline $(30 \mu \mathrm{M})$ in brain slices from control rats. As we reported before (Zhu and Pan, 2004), the non-NMDA EPSCs were completely blocked by the non-NMDAR antagonist CNQX $(10 \mu \mathrm{M}, n=6)$, and the NMDA EPSCs were abolished by the NMDAR antagonist $\operatorname{AP5}(30 \mu \mathrm{M}, n=3)$. To assess the contribution of kainate receptors to the non-NMDA EPSC, we examined the effect of kainate receptor antagonist (S)-1-(2-amino-2-carboxyethyl)-3-(2carboxybenzyl)pyrimidine-2,4-dione (UBP302) on the EPSC. UBP302 (1 $\mu \mathrm{M})$ induced an average inhibition of $14.3 \pm$ $2.0 \%$ in the amplitude of non-NMDA EPSCs (control, $227.8 \pm 37.0 \mathrm{pA}$; UBP302, $194.6 \pm 30.2$ pA; wash, $234.6 \pm$ $40.6 \mathrm{pA} ; n=6 ; t=4.04 ; p<0.05)$.

Bath application of ethanol $(44 \mathrm{~mm})$ produced a significant and reversible inhibition in the amplitude of non-NMDA EPSCs in 11 of 15 cells $(73 \%)$ generally surveyed (control, $168.2 \pm 24.4$ pA; ethanol, $111.4 \pm 16.6$ pA or $33.0 \pm 2.6 \%$; wash, $151.7 \pm 21.9$ $\mathrm{pA} ; n=11 ; p<0.01$ ) (Fig. $1 C$ ). In all 15 of the cells tested, ethanol 
produced an average inhibition of $25.2 \pm 3.4 \%$ (control, $164.8 \pm$ $18.7 \mathrm{pA}$; ethanol, $121.8 \pm 14.2 \mathrm{pA}$; wash, $153.7 \pm 17.2 \mathrm{pA} ; n=15$; $t=4.07 ; p<0.01)$. The inhibition at this ethanol concentration peaked after $10 \mathrm{~min}$ application and could be mostly washed out within $20 \mathrm{~min}$ (Fig. 1E). Ethanol (44 mM) also significantly inhibited the amplitude of NMDAR-mediated EPSCs in four of five neurons tested with a similar time course (control, 253.6 \pm 23.4 pA; ethanol, $162.5 \pm 23.1 \mathrm{pA}$; wash, $224.4 \pm 25.1 \mathrm{pA} ; n=4 ; t=$ 6.46; $p<0.01$ ) (Fig. $1 D, F)$.

Previously, we have characterized three types (A1, A2, and B) of CeA neurons, based on their membrane and pharmacological properties, with the majority of A1-type cells containing the $\mu$-opioid receptor (Zhu and Pan, 2004). Our pooled data showed that ethanol inhibited the non-NMDA EPSCs in most cells of each cell type (A1-type, 31 of 40; A2-type, 34 of 43; B-type, 7/12). This inhibitory effect of ethanol appeared independent on stimulus strength because ethanol (44 mM) induced comparable inhibitions at three different stimulus intensities (Fig. 1G). To compare the sensitivity of non-NMDAR and NMDAR to ethanol, we constructed dose-response curves for the ethanol effects. As shown in Figure $1 \mathrm{H}$, the half-maximal concentration of ethanol was $13.3 \mathrm{~mm}$ for NMDA EPSCs and $14.0 \mathrm{~mm}$ for non-NMDA EPSCs.

As an additional control, we tested the effect of ethanol on AMPA receptor-mediated EPSCs in adult hippocampal CA1 neurons, which are known to be insensitive to ethanol (Mameli et al., 2005). In the presence of the NMDA receptor antagonist AP5 $(30 \mu \mathrm{M})$ and the kainate receptor antagonist UBP302 (1 $\mu \mathrm{M})$, ethanol $(100 \mathrm{~mm})$ had little effect on the remaining glutamate EPSCs in hippocampal CA1 neurons from adult rats (control, $303.1 \pm 30.0$ pA; ethanol, $296.3 \pm 18.7 \mathrm{pA} ; n=6 ; t=0.55 ; p>$ $0.05)$.

\section{Ethanol inhibition involves both presynaptic and postsynaptic sites}

To determine the synaptic site for the ethanol inhibition of glutamate EPSCs, we first used the paradigm of paired-pulse ratio (PPR), which has been widely used in previous studies to determine the involvement of a presynaptic site (Dobrunz and Stevens, 1997; Ungless et al., 2001; Bie et al., 2005; Zhu and Pan, 2005). The control PPR of non-NMDA EPSCs in CeA neurons was $1.52 \pm 0.12(n=8)$, suggesting a general synaptic facilitation $(\mathrm{PPR}>1)$. Ethanol $(44 \mathrm{~mm})$ significantly increased the PPR to $2.17 \pm 0.19$ in these cells $(n=8 ; t=8.81 ; p<0.01)$, indicating that ethanol inhibition of non-NMDA EPSCs involved a decreased synaptic glutamate release from presynaptic terminals (Fig. 2). Consistently, ethanol (44 mM) also increased the PPR of NMDA EPSCs (control, $1.16 \pm 0.1$; ethanol, $1.46 \pm 0.1 ; n=6$; $t=8.16$; $p<0.01$ ) (Fig. 2B).

To further confirm the ethanol inhibition on presynaptic glutamate release and to determine whether a postsynaptic effect was involved, we studied ethanol effects on non-NMDAR-mediated miniature EPSCs (mEPSCs) in the presence of TTX $(1 \mu \mathrm{M})$. Application of ethanol ( $44 \mathrm{~mm}$ ) significantly inhibited the frequency of mEPSCs, suggesting a direct inhibitory effect of ethanol on glutamate release (control, $5.27 \pm 0.53 \mathrm{~Hz}$; ethanol, $2.65 \pm 0.22$ $\mathrm{Hz} ; n=8 ; p<0.01$ ) (Fig. 3). Additionally, ethanol also produced a significant inhibition on the amplitude of mEPSCs in the same cells, indicating an inhibitory action of ethanol on postsynaptic glutamate receptors (control, $21.0 \pm 2.3 \mathrm{pA}$; ethanol, $14.6 \pm 0.8$ pA; $n=8 ; p<0.05$ ) (Fig. 3). These results suggest that ethanol inhibits glutamate synaptic transmission in CeA neurons
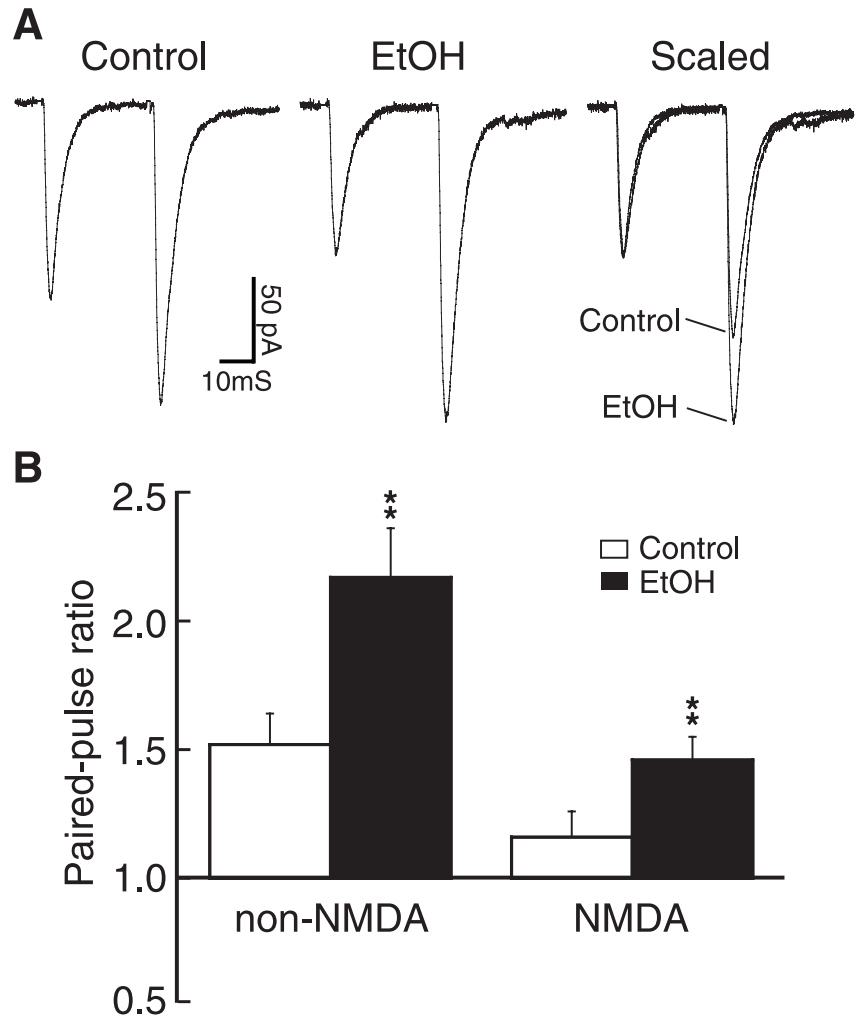

Figure 2. Ethanol increases the PPR of non-NMDA and NMDA EPSCs in CeA neurons. $\boldsymbol{A}$, Representative pairs of EPSCs in the absence (control) and presence of ethanol (EtOH; $44 \mathrm{~mm}$ ), and the same two pairs after being scaled to the amplitude of the first EPSC and superimposed in the two conditions. $\boldsymbol{B}$, Group data of the ethanol effects on the PPR of non-NMDA $(n=8)$ and $\operatorname{NMDA}(n=6)$ EPSCs. ${ }^{* *} p<0.01$. Error bars represent SEM.

through both presynaptic inhibition of glutamate release and postsynaptic inhibition of non-NMDAR and NMDAR.

\section{Presynaptic ethanol inhibition involves N-type $\mathrm{Ca}^{2+}$ channels}

Next, we examined the mechanism for the ethanol-mediated presynaptic inhibition of non-NMDA EPSCs. We have recently shown that activation of $\mu$-opioid receptors inhibits presynaptic glutamate release in these CeA neurons through the phospholipase $A_{2}$ pathway and opening of presynaptic 4-aminopyridine (4-AP)-sensitive potassium channels (Zhu and Pan, 2005). However, 4-AP $(100 \mu \mathrm{M})$ failed to alter ethanol inhibition of nonNMDA EPSCs in these neurons (control in 4-AP, $215.7 \pm 16.2$ $\mathrm{pA}$; plus ethanol, $153.4 \pm 10.1 \mathrm{pA}$; wash in $4-\mathrm{AP}, 192.0 \pm 12.9$ pA; $28.0 \%$ inhibition; $n=11 ; t=7.89 ; p<0.01$ ) (Fig. $4 A, E$ ). In nucleus accumbens neurons, ethanol has been shown to inhibit NMDA EPSCs through presynaptic $\mathrm{GABA}_{\mathrm{B}}$ receptors (Steffensen et al., 2000). In CeA neurons, we found that blockade of $G_{A B A}$ receptors with the selective antagonist (2S)-3-\{[(15)-1-(3,4dichlorophenyl)ethyl] amino-2-hydroxypropyl $\}$ (phenylmethyl) phosphinic acid (CGP55845) $(4 \mu \mathrm{M})$ by itself had no significant effect on the amplitude of non-NMDA EPSCs, nor did it significantly alter the ethanol inhibition of non-NMDA EPSCs (control, $192.4 \pm 25.5 \mathrm{pA}$; CGP55845, $231.5 \pm 32.4 \mathrm{pA} ; p>0.05$; CGP55845 + ethanol, $165.6 \pm 24.3 \mathrm{pA} ;=5.02 ; p<0.01$; wash, $206.8 \pm 29.9$ pA; $28.5 \%$ inhibition; $n=7$ ) (Fig. $4 A, E$ ).

We then tested effects of $\mathrm{Ca}^{2+}$ channel blockers on the ethanol inhibition. Application of nifedipine $(10 \mu \mathrm{M})$ to block L-type $\mathrm{Ca}^{2+}$ channels had no effect either on the amplitude of non- 
A
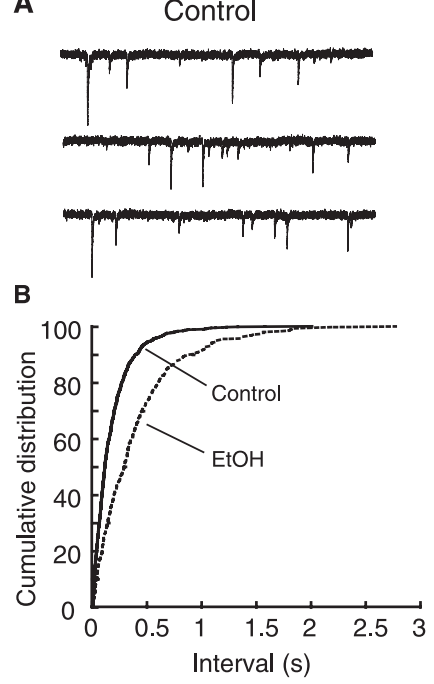
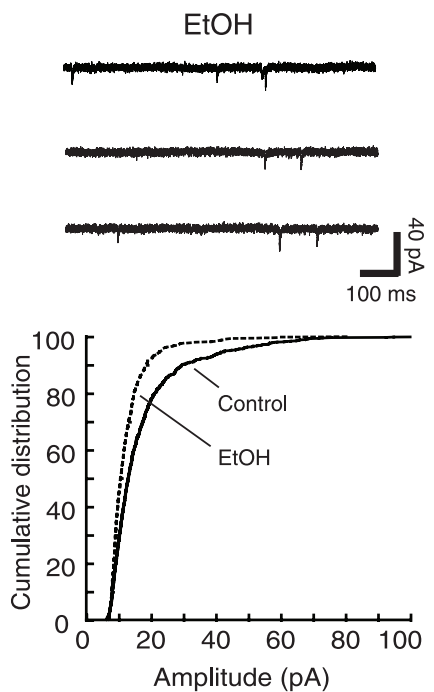

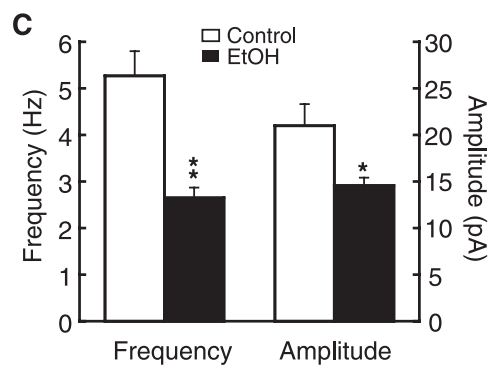

Figure 3. Ethanol inhibits EPSCs through both presynaptic and postsynaptic sites. $A$, Current traces recorded in TTX $(1 \mu \mathrm{M})$, bicuculline $(30 \mu \mathrm{M})$ and AP5 $(10 \mu \mathrm{M})$, showing non-NMDARmediated miniature EPSCs (mEPSCs) in control and in ethanol (EtOH; $44 \mathrm{~mm}$ ). B, Distribution graphs of mEPSC frequency (left) and amplitude (right) in the cell shown in $A$ under the two conditions. $C$, Group data of the ethanol effects on mEPSCS $(n=8) .{ }^{*} p<0.05$; ${ }^{* *} p<0.01$. Error bars represent SEM.

NMDA EPSCs or on the ethanol inhibition (control, $144.7 \pm$ $11.3 \mathrm{pA}$; nifedipine, $140.3 \pm 13.6 \mathrm{pA} ; t=0.94 ; p>0.05$; nifedipine plus ethanol, $100.5 \pm 9.4 \mathrm{pA} ; t=7.58 ; p<0.01$; wash, $128.0 \pm 13.8 \mathrm{pA} ; n=6$ ) (Fig. $4 A, E$ ). Blockade of the P/Q-type $\mathrm{Ca}^{2+}$ channel with $\omega$-agatoxin IVA (100 nM) inhibited the amplitude of non-NMDA EPSCs by an average of $41.1 \pm 4.3 \%$, but it failed to change the ethanol inhibition (control, $216.1 \pm 34.3$ $\mathrm{pA} ; \omega$-agatoxin IVA, $124.0 \pm 15.5 \mathrm{pA} ; t=4.28 ; p<0.05$; $\omega$-agatoxin IVA plus ethanol, $67.5 \pm 10.4 \mathrm{pA} ; n=5, t=4.03 ; p<$ 0.05) (Fig. $4 B, E$ ).

Blocking the $\mathrm{N}$-type $\mathrm{Ca}^{2+}$ channel with $\omega$-conotoxin GVIA (1 $\mu \mathrm{M}$ ) also reduced the baseline EPSC by $42.3 \pm 5.4 \%$ (control, $275.3 \pm 29.3 \mathrm{pA} ; \omega$-conotoxin GVIA, $159.4 \pm 23.7 \mathrm{pA} ; n=5 ; t=$ 5.64; $p<0.01$ ) (Fig. 4C). In contrast, in the presence of $\omega$-conotoxin GVIA, ethanol produced a smaller inhibition $(13.7 \pm 3.4 \%)$ in the amplitude of non-NMDA EPSCs (control in $\omega$-conotoxin GVIA, $187.6 \pm 21.7 \mathrm{pA}$; plus ethanol, $158.6 \pm 20.2$ $\mathrm{pA} ; n=7 ; t=2.99 ; p<0.05$ ) (Fig. $4 C, E$ ). This inhibition was significantly decreased when compared with the inhibition by ethanol alone $(33.0 \pm 2.6 \% ; t=4.52 ; p<0.01)$, indicating that blocking the $\mathrm{N}$-type $\mathrm{Ca}^{2+}$ channel significantly reduced the ethanol effect. Furthermore, $\omega$-conotoxin GVIA $(1 \mu \mathrm{M})$ completely abolished the ethanol-induced increase in the PPR (control in $\omega$-conotoxin GVIA, $1.70 \pm 0.10$; plus ethanol, $1.71 \pm 0.11 ; n=$ $11 ; t=0.45 ; p>0.05$ ) (Fig. $4 D$ ). Additionally, the N-type $\mathrm{Ca}^{2+}$ channel blocker significantly reduced the frequency of baseline mEPSCs by an average of $51.0 \pm 2.2 \%$ but did not change the

mEPSC amplitude (Fig. $4 F$ ), indicating a presynaptic effect. In the presence of $\omega$-conotoxin GVIA $(1 \mu \mathrm{M})$, ethanol was no longer effective on the mEPSC frequency but still induced an inhibition on the mEPSC amplitude (Fig. $4 F$ ). These data indicate that the presynaptic component of the ethanol inhibition was occluded by $\omega$-conotoxin GVIA, and the remaining inhibition was postsynaptic. Together, these results suggest that although both the $\mathrm{P} / \mathrm{Q}$-type and the $\mathrm{N}$-type $\mathrm{Ca}^{2+}$ channels are important for glutamate release, only presynaptic $\mathrm{N}$-type $\mathrm{Ca}^{2+}$ channels are involved in the ethanol inhibition of non-NMDA EPSCs in CeA neurons.

\section{Ethanol produces a behavioral effect of reward}

In the following behavioral studies, we examined the role of CeA non-NMDA synaptic transmission in ethanol-induced reward behavior. The widely used procedure of conditioned place preference (CPP) was employed to quantitatively measure the rewarding effect of ethanol in rats in vivo. In tests of baseline preference before ethanol conditioning, rats showed a consistent preference for the black chamber with rod grid floor over the white chamber with mesh floor (black/grid floor, $75.2 \pm 1.5 \%$; white/mesh floor, $24.8 \pm 1.5 \% ; n=27 ; F=283 ; p<0.01)$. Ethanol conditioning was paired with the nonpreferred chamber to avoid a possible effect of upward limit in the time a rat might spend in the preferred chamber, or ceiling effect (Cunningham et al., 2003). In pre-conditioning tests, rats spent an average of $283 \pm 30 \mathrm{~s}$ in the nonpreferred chamber during a $30 \mathrm{~min}$ test period. After ethanol conditioning for $14 \mathrm{~d}$, the time the same rat spent in the same chamber paired with ethanol administration $(0.5 \mathrm{~g} / \mathrm{kg}$, i.p. ) significantly increased to $483 \pm 39 \mathrm{~s}$ during the 30 min postconditioning test $(n=14 ; F=14.1 ; p<0.01)$ (Fig. 5$)$. In contrast, the same conditioning with saline in a separate group of rats did not change the preference behavior (pre-test, $296 \pm 30 \mathrm{~s}$; post-test, $303 \pm 38 \mathrm{~s} ; n=13 ; F=0.18 ; p>0.05)$. Moreover, between-group comparison showed that ethanol-conditioned rats spent significantly more time than saline-conditioned rats did in the nonpreferred chamber $(p<0.01)$ (Fig. 5), confirming the ethanol-induced CPP behavior of alcohol reward.

To exclude a possible effect of baseline preference bias, we paired ethanol conditioning with the preferred chamber in another group of rats. Similarly, the same ethanol conditioning but paired with the preferred chamber significantly increased the time the rat spent in the ethanol-paired chamber (pre-test, $694 \pm$ $78 \mathrm{~s}$; or $65.8 \pm 1.0 \%$; post-test, $1041 \pm 65 \mathrm{~s}$; or $80.2 \pm 2.8 \%$; $n=$ $6 ; F=11.5 ; p<0.01)$. To further validate the rewarding effect of ethanol in this CPP model, we substituted ethanol with morphine, a strong reinforcing opioid, in the conditioning procedure. Morphine conditioning with the same procedure induced a significant CPP (pre-test, $318 \pm 63$ s; post-test, $591 \pm 72 \mathrm{~s} ; n=5$; $F=57.2 ; p<0.01$ ) (Fig. 5). These results indicate that the ethanol treatment and conditioning with repeated systemic application of ethanol produce a significant rewarding effect as measured by the CPP behavior.

\section{Ethanol-induced CPP is associated with an increase in non- NMDAR-mediated synaptic transmission}

Next, we examined whether non-NMDAR-mediated synaptic transmission in the CeA was altered by the ethanol treatment and conditioning that induced the CPP behavior. After a postconditioning test to confirm the ethanol-induced CPP behavior in a rat, CeA slices were obtained from the rat exhibiting the CPP behavior, and the properties of non-NMDA EPSCs in CeA neurons were examined and compared with those in CeA slices from 
saline-conditioned control rats. We used PPR analysis to take advantage of less variance in PPR among individual cells between different slice groups, as we did in our previous studies (Bie et al., 2005; Ma and Pan, 2006). In CeA slices from salinetreated rats, the averaged PPR in CeA neurons was $1.63 \pm 0.07(n=17)$. However, in $\mathrm{CeA}$ slices from ethanol-treated rats with CPP, the averaged PPR was significantly decreased in CeA neurons (1.18 \pm $0.06 ; n=15 ; t=4.51 ; p<0.01$ ) (Fig. 6). Similarly, repeated morphine treatments and conditioning that induced CPP also significantly reduced the PPR (control, $1.63 \pm 0.07$; morphine-conditioned, $1.24 \pm 0.05 ; n=12 ; t=4.06 ; p<0.01)$ (Fig. $6 B$ ). In contrast, treatment with a single ethanol injection at the same dose did not significantly change the PPR (Fig. $6 B)$. These results indicate that repeated administration of systemic ethanol causes a neuroadaptive increase in glutamate synaptic release and non-NMDAR-mediated synaptic transmission in the $\mathrm{CeA}$ and a concomitant reward behavior in rats.

\section{CeA non-NMDAR is required for} ethanol-induced CPP behavior If the increased non-NMDAR-mediated synaptic transmission is necessary for the ethanol-induced CPP, blocking CeA nonNMDAR should antagonize the reward behavior. We then tested this hypothesis in rats exhibiting the ethanol-induced CPP behavior in vivo. The same ethanol-conditioning procedure was conducted in rats implanted with two single cannulas, each aiming at the CeA of each side. One day after the postconditioning test with demonstrated CPP in an ethanol-conditioned rat, saline or the non-NMDAR antagonist CNQX was bilaterally microinjected into the CeA, followed by a CPP test. Microinjection of saline did not affect the ethanol-induced CPP behavior (pre-test, $267 \pm 49$ s; post-test, $473 \pm 53 \mathrm{~s} ; p<0.01$; post-CeA injection, $419 \pm 49 \mathrm{~s} ; F=0.067 ; p>0.05$ when compared with post-test; $n=4)($ Fig. $7 A)$. This indicates that the behavior of ethanolinduced CPP persists one day after the post-test without additional ethanol administration. However, in a separate, comparable group of rats, bilateral microinjection of CNQX ( $1.5 \mu \mathrm{g}$ in 0.5 $\mu$ l each side) into the CeA abolished the CPP, significantly decreasing the time the rat spent in the ethanol-paired chamber to a level below the time in the pre-test (pre-test, $327 \pm 44$ s; post-test, $502 \pm 56 \mathrm{~s}, F=17.5, p<0.01$; post-CeA injection, $226 \pm 49 \mathrm{~s}$, $n=7, F=14.4, p<0.01$ when compared with the post-test) (Fig. $7 A)$. In contrast, the same CeA microinjection of CNQX at the same dose in saline-conditioned rats had no significant effect on the baseline preference behavior, excluding a significant role of baseline synaptic activity of CeA non-NMDAR in the preference behavior (pre-test, $348 \pm 51 \mathrm{~s}$; post-test, $356 \pm 46 \mathrm{~s} ; p>0.05$; post-CeA injection, $315 \pm 36 \mathrm{~s} ; n=4 ; F=5.9 ; p>0.05$ when compared with the post-test) (Fig. $7 B$ ).

Next, we examined whether the NMDAR in the CeA was also involved in the ethanol-induced CPP behavior. In another group of rats, ethanol treatment and conditioning again induced CPP

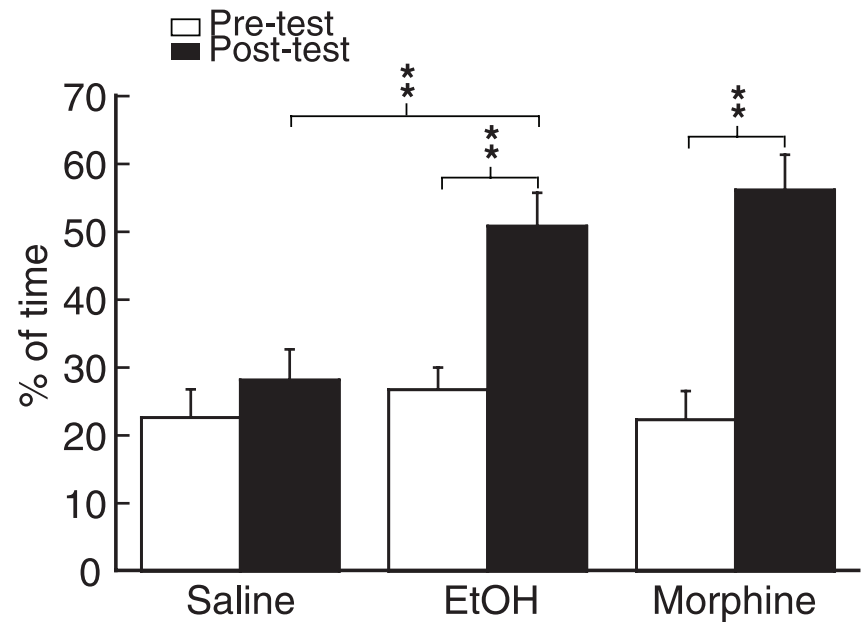

Figure 5. Ethanol (EtOH) induces reward behavior of CPP. A CPP test was performed before (pre-test) and after (post-test) conditioning with saline, ethanol, or morphine. Data are expressed as the percentage of time a rat spent in the saline-paired (saline control group) and ethanol- or morphine-paired chamber versus the total time the rat spent in the two test chambers. Data were compared between pre-test and post-test. ${ }^{* *} p<0.01$. Error bars represent SEM.

(pre-test, $292 \pm 30$ s; post-test, $477 \pm 36 s ; n=5 ; F=8.3 ; p<$ 0.05). One day after the post-test, bilateral CeA microinjection of the NMDAR antagonist AP5 ( $1 \mu \mathrm{g}$ in $0.5 \mu \mathrm{l}$ each side) reversed the ethanol-induced CPP $(320 \pm 42 s ; n=5 ; F=12.0 ; p<0.05$ 
A

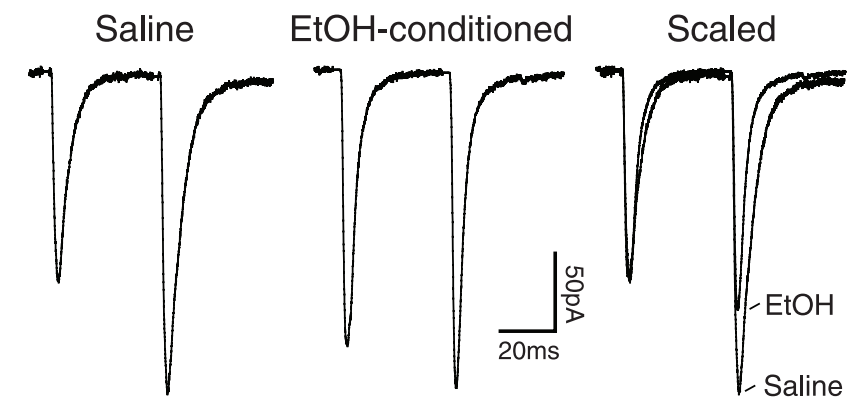

B

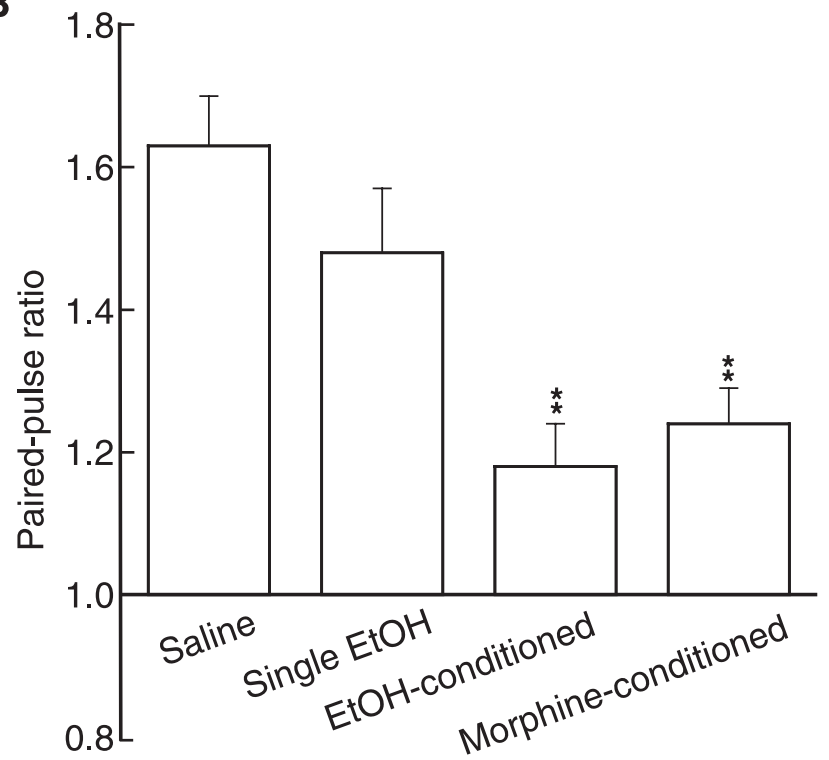

Figure 6. Glutamate synaptic transmission is increased in CeA neurons from ethanol (EtOH)treated rats with CPP behavior. $A$, Representative non-NMDA EPSC pairs in CeA neurons from saline- and ethanol-conditioned rats and the same pairs after being scaled and superimposed. $B$, Group data of the PPR in CeA neurons from saline-conditioned rats $(n=17)$, rats after single ethanol treatment $(n=15)$, chronic ethanol-conditioned rats $(n=15)$, and morphineconditioned rats $(n=12) .{ }^{* *} p<0.01$ compared with the saline group. Error bars represent SEM.

when compared with the post-test) (Fig. 7A). These results indicate that blockade of CeA non-NMDAR, NMDAR, and the adaptive increase in their synaptic transmission inhibits ethanolinduced reward behavior. Finally, we assessed the role of CeA non-NMDAR in morphine-induced CPP behavior in a separate group of rats. After similar experimental conditions and procedures, bilateral CeA microinjection of CNQX at the same dose also mostly inhibited the morphine-induced CPP behavior (pretest, $267 \pm 39 \mathrm{~s}$; post-test, $579 \pm 75 \mathrm{~s}, F=42.6, p<0.01$; postCeA injection, $285 \pm 41 \mathrm{~s}, n=6, F=51.6, p<0.01$ ) (Fig. 7B).

\section{Discussion}

The present study has demonstrated that acute ethanol at a behaviorally relevant concentration of $44 \mathrm{~mm}$ inhibits nonNMDAR-mediated synaptic transmission through both presynaptic and postsynaptic sites in CeA neurons. The ethanol inhibition of presynaptic glutamate release involves $\mathrm{N}$-type $\mathrm{Ca}^{2+}$ channels. Behaviorally, chronic ethanol that induces the CPP behavior enhances glutamate synaptic transmission in CeA neurons, and blockade of CeA non-NMDAR and NMDAR inhibits the ethanol-induced CPP behavior. These results suggest that although acute alcohol inhibits synaptic function of CeA non-
A $\square$ Pre-test

- Post-test

ש] CeA injection
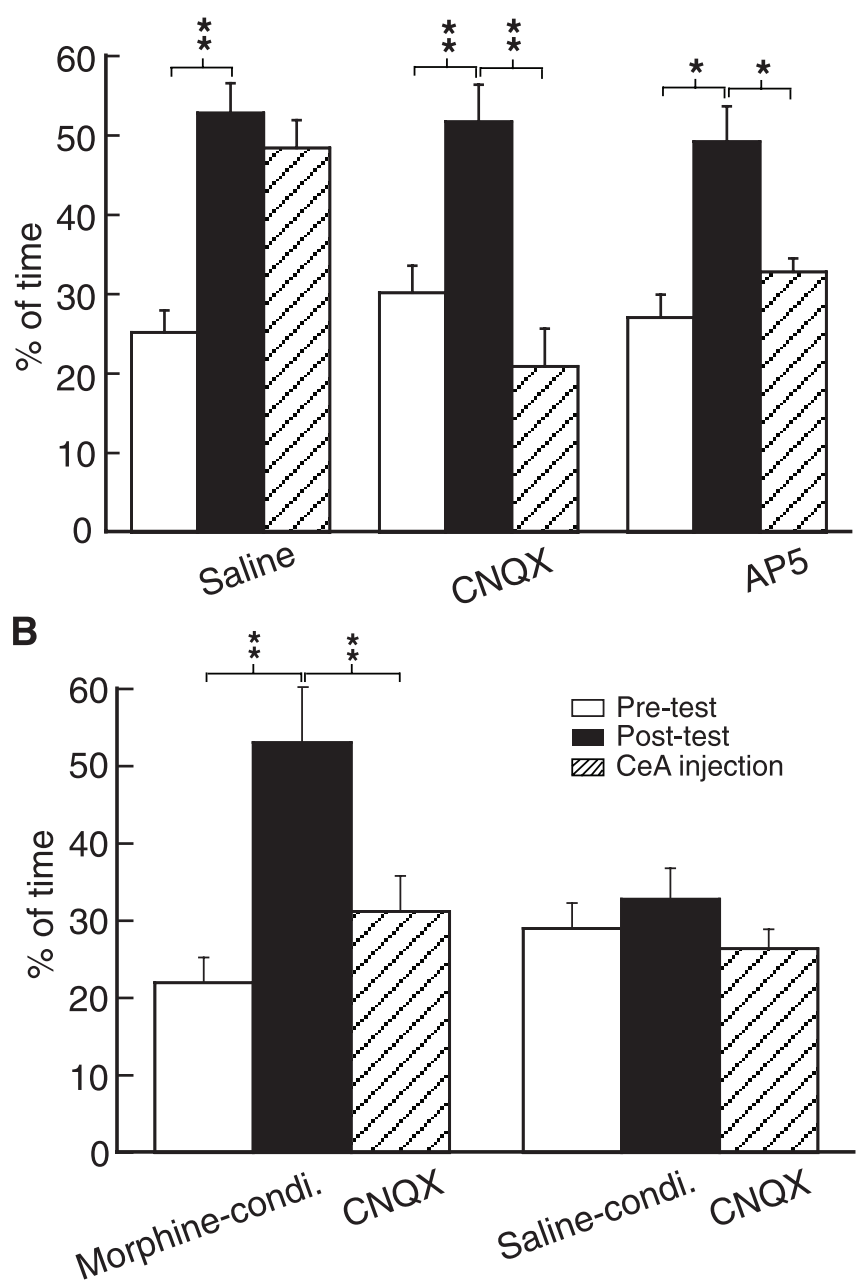

Figure 7. Blockade of CeA glutamate receptors eliminates both ethanol- and morphineinduced reward behavior. $A$, Effects of bilateral microinjection of saline, CNQX (1.5 $\mu \mathrm{g}$ in $0.5 \mu \mathrm{l}$ each side) and AP5 ( $1 \mu \mathrm{g}$ in $0.5 \mu$ leach side) into the CeA on ethanol-induced CPP in ethanolconditioned rats. CeA microinjection was made $1 \mathrm{~d}$ after the postconditioning test and was followed by a CPP test. $\boldsymbol{B}$, Effects of CeA microinjection of CNQX at the same dose in morphineand saline-conditioned rats. ${ }^{*} p<0.05 ;{ }^{* *} p<0.01$. Error bars represent SEM.

NMDAR, chronic alcohol causes an adaptive increase in CeA glutamate synaptic activity, which is required for the alcoholinduced reward behavior.

\section{Acute alcohol-induced inhibition of glutamate receptor functions}

Postsynaptically, the NMDAR is commonly inhibited by acute alcohol in many types of central neurons, including those in the CeA (Morrisett and Swartzwelder, 1993; Nie et al., 1994; Calton et al., 1998; Steffensen et al., 2000; Woodward, 2000; Criswell et al., 2003; Roberto et al., 2004, 2005; Mameli et al., 2005). In contrast, there are fewer reports of alcohol inhibition of the AMPAR, a dominant non-NMDAR in central neurons. Acute ethanol has been shown to inhibit the function of recombinant AMPAR in Xenopus oocytes (Dildy-Mayfield and Harris, 1992; Akinshola et al., 2003), the AMPAR in cultured cortical neurons (Moykkynen et al., 2003), and in CeA neurons (Roberto et al., 2004). Another recent study demonstrates an age-dependent alcohol inhibition of AMPAR-mediated currents only in neonatal, 
but not mature, hippocampal neurons (Mameli et al., 2005). Thus, it appears that the CeA is one of the rare sites in the adult brain at which alcohol inhibits the synaptic functions of both AMPAR and NMDAR. Given the enhanced synaptic function of non-NMDAR in activity-dependent or cocaine-induced synaptic plasticity (Hayashi et al., 2000; Ungless et al., 2001), the rare inhibition of CeA non-NMDAR by alcohol may indicate a critical role of CeA non-NMDAR in alcohol reward and addiction. Alcohol inhibits NMDAR functions likely by allosteric modulation of the channel gating (Wright et al., 1996; Woodward, 2000; Honse et al., 2004; Smothers and Woodward, 2006). The molecular mechanisms involved in alcohol inhibition of postsynaptic non-NMDAR remain largely unknown at present.

The mechanisms for presynaptic alcohol inhibition of glutamate release are just emerging. In nucleus accumbens neurons, alcohol reduces NMDA neurotransmission by activating presynaptic $\mathrm{GABA}_{\mathrm{B}}$ receptors (Steffensen et al., 2000). In neonatal hippocampus, alcohol inhibition of NMDAR-mediated currents involves presynaptic $\mathrm{N}$-type $\mathrm{Ca}^{2+}$ channels (Mameli et al., 2005). A recent study using PPR analysis in normal CeA neurons indicates that acute ethanol inhibits glutamate synaptic currents through a postsynaptic site (Roberto et al., 2004). The present study with analysis of both mEPSCs and PPR argues that the alcohol inhibition is mediated through both presynaptic and postsynaptic sites in CeA neurons under control conditions. The presynaptic inhibition is evidenced by direct ethanol inhibition of mEPSC frequency and by ethanol enhancement in the PPR of non-NMDA EPSCs. It is further supported by $\omega$-conotoxin GVIA antagonism of both ethanol effects on mEPSC frequency and PPR, suggesting the involvement of presynaptic $\mathrm{N}$-type $\mathrm{Ca}^{2+}$ channels. The reasons are unclear for the discrepancy regarding the involvement of presynaptic sites in the ethanol inhibition of glutamate EPSCs in normal CeA neurons. They may include technical differences in recording configurations (sharp-electrode vs whole-cell recordings) and analytic methods of glutamate EPSCs (PPR vs mEPSCs), resulting in a difference in the time course of EPSCs for the determination of PPR.

\section{Chronic alcohol-induced upregulation of glutamate receptor functions}

Glutamate synapses undergo neuroadaptive changes after prolonged exposure to many drugs of abuse (Nestler, 2001; Siggins et al., 2003). Glutamate synaptic plasticity also plays a critical role in alcohol reinforcement and dependence (Siggins et al., 2003, 2005). Postsynaptically, it has been widely reported that chronic alcohol increases NMDAR functions with or without changes in the expression levels of NMDAR mRNA or proteins (Trevisan et al., 1994; Follesa and Ticku, 1996; Chandler et al., 1997; Chen et al., 1997; Rudolph et al., 1997; Ferreira et al., 2001; Kumari, 2001; Floyd et al., 2003; Roberto et al., 2005). It has been shown that synaptic NMDAR, but not extrasynaptic NMDAR, is targeted by chronic ethanol (Carpenter-Hyland et al., 2004). However, there have been few reports concerning the effects of chronic alcohol on non-NMDAR functions. Although ethanol inhibition of nonNMDAR-mediated neurotransmission is reportedly not altered by chronic ethanol in CeA neurons (Roberto et al., 2004), a crucial role of the AMPAR in alcohol-seeking behavior has been demonstrated in a very recent study using mice lacking the AMPAR subunit glutamate receptor C (GluR-C) (SanchisSegura et al., 2006).

Presynaptically, the effect of chronic alcohol on glutamate synaptic release has been examined only recently. Basal glutamate content as revealed by microdialysis in the CeA is significantly increased in rats exposed to chronic ethanol (Roberto et al., 2004). The present study, characterizing the difference in the PPR property of CeA neurons between control rats and rats with the ethanol-induced CPP behavior, provides relatively direct evidence for a chronic alcohol-induced, behaviorally relevant increase in non-NMDAR-mediated synaptic activity. In our previous study, the same analysis has been successfully used for identification of chronic morphine-induced increase in presynaptic glutamate release, because usually large variance in miniature synaptic currents among individual neurons prevents their between-group comparison of drug-treated and control neurons (Bie et al., 2005). Importantly, previously reported presynaptic and postsynaptic changes in the functions of glutamate receptor were induced by chronic alcohol administered to either cultured cells or to animals without a direct link to the animal's behaviorrelated alcohol reward. The increase in glutamate synaptic release found in the current study is present in CeA neurons from the rats displaying alcohol-induced CPP behavior, thus directly associating the synaptic change in the CeA with the behavior of alcohol reward.

\section{Role of CeA non-NMDAR in alcohol reward}

Among the multiple targets of acute and chronic alcohol, GABA receptors and ionotropic glutamate receptors are particularly important in the mechanisms of alcohol addiction (Narahashi et al., 2001; Koob, 2004; Siggins et al., 2005). Behavioral studies have demonstrated that the CeA is the most sensitive brain site for $\mathrm{GABA}_{\mathrm{A}}$ receptor antagonists to reduce alcohol consumption in rodent models (Hyytia and Koob, 1995; Koob, 2004). This can be attributed largely to the later identified augmenting effects of acute and chronic alcohol on presynaptic GABA release and postsynaptic $\mathrm{GABA}_{\mathrm{A}}$ receptor function in CeA neurons (Roberto et al., 2003; Nie et al., 2004).

Relatively, much less is known about the roles of the glutamate neurotransmission, particularly the non-NMDAR, in alcohol addiction. The direct evidence is lacking for the behavioral consequence of those synaptic actions of alcohol on CeA glutamate receptors in alcohol reward and addiction. Our behavioral data provide a direct link between cellular effects of alcohol and alcohol-induced reward behavior through CeA neurons, indicating that an adaptive increase in non-NMDAR-mediated synaptic transmission in CeA neurons is a necessary component mediating the alcohol-induced CPP behavior. Our findings also underscore the important role of predominant glutamatergic inputs from the basolateral complex of the amygdala to CeA neurons, as identified in our previous study (Zhu and Pan, 2004), in the behavior of alcohol reward. Supporting a general role of AMPAR in the reward function of the CeA and in alcohol addiction, recent studies using AMPAR subunit knock-out mice show that the GluR-B subunit is important for stimulus-reward learning behavior, and the GluR-C subunit is involved in alcohol-seeking behavior and relapse (Mead and Stephens, 2003; Sanchis-Segura et al., 2006).

It is worth noting that CeA application of CNQX completely reversed the $\mathrm{CPP}$ behavior. Given that $\mathrm{CeA} \mathrm{GABA}_{\mathrm{A}}$ receptors are also critically involved in alcohol reward, and blocking CeA NMDAR also largely inhibited the CPP, the reasons for the complete reversal by CNQX are unknown, and additional studies on the functional interactions between these receptors are necessary. CNQX has been shown to increase synaptic activity of GABAergic interneurons in developing hippocampus (Maccaferri and Dingledine, 2002). Whether that was also the case in the CeA and the enhanced GABA synaptic activity contributed to the 
behavioral effect of CNQX is unclear at present. It is intriguing to consider the behavioral function of the ethanol-induced increase in CeA glutamate synaptic transmission. As the CPP-associated increase broadly occurs in CeA glutamate synapses, it is currently unknown whether it would occlude or synergize with similar effects produced by other drugs of abuse, such as opioids. Although it is likely that after this ethanol-induced synaptic change, CeA neurons still have capacity to synaptically respond to other similar drugs of abuse, how they may respond differently, and what are the synaptic and behavioral outcomes, are functionally interesting issues to be explored.

In summary, it appears that, distinct from many other brain sites at which the non-NMDAR is spared from alcohol actions, the non-NMDAR in the CeA is an important target of acute alcohol, and the neuroadaptive increase in the synaptic function of CeA non-NMDAR is one of the key components underlying alcohol-induced reward behavior.

\section{References}

Akinshola BE, Yasuda RP, Peoples RW, Taylor RE (2003) Ethanol sensitivity of recombinant homomeric and heteromeric AMPA receptor subunits expressed in Xenopus oocytes. Alcohol Clin Exp Res 27:1876-1883.

Baxter MG, Murray EA (2002) The amygdala and reward. Nat Rev Neurosci 3:563-573.

Biala G, Kotlinska J (1999) Blockade of the acquisition of ethanol-induced conditioned place preference by $\mathrm{N}$-methyl-D-aspartate receptor antagonists. Alcohol Alcohol 34:175-182.

Bie B, Peng Y, Zhang Y, Pan ZZ (2005) cAMP-mediated mechanisms for pain sensitization during opioid withdrawal. J Neurosci 25:3824-3832.

Bienkowski P, Kuca P, Piasecki J, Kostowski W (1996) Low dose of ethanol induces conditioned place preference in rats after repeated exposures to ethanol or saline injections. Alcohol Alcohol 31:547-553.

Bozarth MA (1990) Evidence for the rewarding effects of ethanol using the conditioned place preference method. Pharmacol Biochem Behav 35:485-487.

Calton JL, Wilson WA, Moore SD (1998) Magnesium-dependent inhibition of $N$-methyl-D-aspartate receptor-mediated synaptic transmission by ethanol. J Pharmacol Exp Ther 287:1015-1019.

Carpenter-Hyland EP, Woodward JJ, Chandler LJ (2004) Chronic ethanol induces synaptic but not extrasynaptic targeting of NMDA receptors. J Neurosci 24:7859-7868.

Carta M, Ariwodola OJ, Weiner JL, Valenzuela CF (2003) Alcohol potently inhibits the kainate receptor-dependent excitatory drive of hippocampal interneurons. Proc Natl Acad Sci USA 100:6813-6818.

Chandler LJ, Sutton G, Norwood D, Sumners C, Crews FT (1997) Chronic ethanol increases $N$-methyl-D-aspartate-stimulated nitric oxide formation but not receptor density in cultured cortical neurons. Mol Pharmacol 51:733-740.

Chen X, Michaelis ML, Michaelis EK (1997) Effects of chronic ethanol treatment on the expression of calcium transport carriers and NMDA/glutamate receptor proteins in brain synaptic membranes. J Neurochem 69:1559-1569.

Criswell HE, Ming Z, Griffith BL, Breese GR (2003) Comparison of effect of ethanol on $N$-methyl-D-aspartate- and GABA-gated currents from acutely dissociated neurons: absence of regional differences in sensitivity to ethanol. J Pharmacol Exp Ther 304:192-199.

Cunningham CL, Henderson CM, Bormann NM (1998) Extinction of ethanol-induced conditioned place preference and conditioned place aversion: effects of naloxone. Psychopharmacology (Berl) 139:62-70.

Cunningham CL, Ferree NK, Howard MA (2003) Apparatus bias and place conditioning with ethanol in mice. Psychopharmacology (Berl) 170:409-422.

Dildy-Mayfield JE, Harris RA (1992) Comparison of ethanol sensitivity of rat brain kainate, DL-alpha-amino-3-hydroxy-5-methyl-4-isoxalone proprionic acid and $\mathrm{N}$-methyl-D-aspartate receptors expressed in Xenopus oocytes. J Pharmacol Exp Ther 262:487-494.

Dobrunz LE, Stevens CF (1997) Heterogeneity of release probability, facilitation, and depletion at central synapses. Neuron 18:995-1008.

Fadda F, Rossetti ZL (1998) Chronic ethanol consumption: from neuroadaptation to neurodegeneration. Prog Neurobiol 56:385-431.
Ferreira VM, Frausto S, Browning MD, Savage DD, Morato, Gs, Valenzuela CF (2001) Ionotropic glutamate receptor subunit expression in the rat hippocampus: lack of an effect of a long-term ethanol exposure paradigm. Alcohol Clin Exp Res 25:1536-1541.

Floyd DW, Jung KY, McCool BA (2003) Chronic ethanol ingestion facilitates $N$-methyl-D-aspartate receptor function and expression in rat lateral/basolateral amygdala neurons. J Pharmacol Exp Ther 307:1020-1029.

Follesa P, Ticku MK (1996) Chronic ethanol-mediated up-regulation of the $\mathrm{N}$-methyl-D-aspartate receptor polypeptide subunits in mouse cortical neurons in culture. J Biol Chem 271:13297-13299.

Gottfried JA, O’Doherty J, Dolan RJ (2003) Encoding predictive reward value in human amygdala and orbitofrontal cortex. Science 301:1104-1107.

Hayashi Y, Shi SH, Esteban JA, Piccini A, Poncer JC, Malinow R (2000) Driving AMPA receptors into synapses by LTP and CaMKII: requirement for GluR1 and PDZ domain interaction. Science 287:2262-2267.

Honse Y, Ren H, Lipsky RH, Peoples RW (2004) Sites in the fourth membrane-associated domain regulate alcohol sensitivity of the NMDA receptor. Neuropharmacology 46:647-654.

Hyytia P, Koob GF (1995) GABA $_{\mathrm{A}}$ receptor antagonism in the extended amygdala decreases ethanol self-administration in rats. Eur J Pharmacol 283:151-159.

Koob GF (2004) A role for GABA mechanisms in the motivational effects of alcohol. Biochem Pharmacol 68:1515-1525.

Koob GF, Sanna PP, Bloom FE (1998) Neuroscience of addiction. Neuron 21:467-476.

Krystal JH, Petrakis IL, Mason G, Trevisan L, D'Souza DC (2003) $\mathrm{N}$-methyl-D-aspartate glutamate receptors and alcoholism: reward, dependence, treatment, and vulnerability. Pharmacol Ther 99:79-94.

Kumari M (2001) Differential effects of chronic ethanol treatment on $\mathrm{N}$-methyl-D-aspartate R1 splice variants in fetal cortical neurons. J Biol Chem 276:29764-29771.

Lovinger DM, White G, Weight FF (1989) Ethanol inhibits NMDAactivated ion current in hippocampal neurons. Science 243:1721-1724.

Ma J, Pan ZZ (2006) Contribution of brainstem GABA(A) synaptic transmission to morphine analgesic tolerance. Pain 122:163-173.

Maccaferri G, Dingledine R (2002) Complex effects of CNQX on CA1 interneurons of the developing rat hippocampus. Neuropharmacology 43:523-529.

Mameli M, Zamudio PA, Carta M, Valenzuela CF (2005) Developmentally regulated actions of alcohol on hippocampal glutamatergic transmission. J Neurosci 25:8027-8036.

Masood K, Wu C, Brauneis U, Weight FF (1994) Differential ethanol sensitivity of recombinant $N$-methyl-D-aspartate receptor subunits. Mol Pharmacol 45:324-329.

Matsuzawa S, Suzuki T, Misawa M, Nagase H (1999) Different roles of mu-, delta- and kappa-opioid receptors in ethanol-associated place preference in rats exposed to conditioned fear stress. Eur J Pharmacol 368:9-16.

Mead AN, Stephens DN (2003) Involvement of AMPA receptor GluR2 subunits in stimulus-reward learning: evidence from glutamate receptor gria2 knock-out mice. J Neurosci 23:9500-9507.

Morrisett RA, Swartzwelder HS (1993) Attenuation of hippocampal longterm potentiation by ethanol: a patch-clamp analysis of glutamatergic and GABAergic mechanisms. J Neurosci 13:2264-2272.

Moykkynen T, Korpi ER, Lovinger DM (2003) Ethanol inhibits alphaamino-3-hydyroxy-5-methyl-4-isoxazolepropionic acid (AMPA) receptor function in central nervous system neurons by stabilizing desensitization. J Pharmacol Exp Ther 306:546-555.

Narahashi T, Kuriyama K, Illes P, Wirkner K, Fischer W, Muhlberg K, Scheibler P, Allgaier C, Minami K, Lovinger D, Lallemand F, Ward RJ, DeWitte P, Itatsu T, Takei Y, Oide H, Hirose M, Wang XE, Watanabe S, Tateyama M, et al. (2001) Neuroreceptors and ion channels as targets of alcohol. Alcohol Clin Exp Res 25:182S-188S.

Nestler EJ (2001) Molecular basis of long-term plasticity underlying addiction. Nat Rev Neurosci 2:119-128.

Nie Z, Madamba SG, Siggins GR (1994) Ethanol inhibits glutamatergic neurotransmission in nucleus accumbens neurons by multiple mechanisms. J Pharmacol Exp Ther 271:1566-1573.

Nie Z, Schweitzer P, Roberts AJ, Madamba SG, Moore SD, Siggins GR (2004) Ethanol augments GABAergic transmission in the central amygdala via CRF1 receptors. Science 303:1512-1514. 
Paxinos G, Watson C (1986) The rat brain in stereotaxic coordinates, Ed 2. Sydney: Academic.

Roberto M, Madamba SG, Moore SD, Tallent MK, Siggins GR (2003) Ethanol increases GABAergic transmission at both pre- and postsynaptic sites in rat central amygdala neurons. Proc Natl Acad Sci USA 100:2053-2058.

Roberto M, Schweitzer P, Madamba SG, Stouffer DG, Parsons LH, Siggins GR (2004) Acute and chronic ethanol alter glutamatergic transmission in rat central amygdala: an in vitro and in vivo analysis. J Neurosci 24:1594-1603.

Roberto M, Bajo M, Crawford E, Madamba SG, Siggins GR (2005) Chronic ethanol exposure and protracted abstinence alter NMDA receptors in central amygdala. Neuropsychopharmacology 31:988-996.

Rudolph JG, Walker DW, Iimuro Y, Thurman RG, Crews FT (1997) NMDA receptor binding in adult rat brain after several chronic ethanol treatment protocols. Alcohol Clin Exp Res 21:1508-1519.

Sanchis-Segura C, Borchardt T, Vengeliene V, Zghoul T, Bachteler D, Gass P, Sprengel R, Spanagel R (2006) Involvement of the AMPA receptor GluR-C subunit in alcohol-seeking behavior and relapse. J Neurosci 26:1231-1238.

See RE, Fuchs RA, Ledford CC, McLaughlin J (2003) Drug addiction, relapse, and the amygdala. Ann NY Acad Sci 985:294-307.

Siggins GR, Martin G, Roberto M, Nie Z, Madamba S, De Lecea L (2003) Glutamatergic transmission in opiate and alcohol dependence. Ann NY Acad Sci 1003:196-211.

Siggins GR, Roberto M, Nie Z (2005) The tipsy terminal: presynaptic effects of ethanol. Pharmacol Ther 107:80-98.

Smothers CT, Woodward JJ (2006) Effects of amino acid substitutions in transmembrane domains of the NR1 subunit on the ethanol inhibition of recombinant $N$-methyl-D-aspartate receptors. Alcohol Clin Exp Res 30:523-530.
Steffensen SC, Nie Z, Criado JR, Siggins GR (2000) Ethanol inhibition of $N$-methyl-D-aspartate responses involves presynaptic gammaaminobutyric acid(B) receptors. J Pharmacol Exp Ther 294:637-647.

Tabakoff B, Hoffman PL (1996) Alcohol addiction: an enigma among us. Neuron 16:909-912.

Trevisan L, Fitzgerald LW, Brose N, Gasic GP, Heinemann SF, Duman RS, Nestler EJ (1994) Chronic ingestion of ethanol up-regulates NMDAR1 receptor subunit immunoreactivity in rat hippocampus. J Neurochem 62:1635-1638.

Trujillo KA, Akil H (1991) Inhibition of morphine tolerance and dependence by the NMDA receptor antagonist MK-801. Science 251:85-87.

Tzschentke TM (1998) Measuring reward with the conditioned place preference paradigm: a comprehensive review of drug effects, recent progress and new issues. Prog Neurobiol 56:613-672.

Ungless MA, Whistler JL, Malenka RC, Bonci A (2001) Single cocaine exposure in vivo induces long-term potentiation in dopamine neurons. Nature 411:583-587.

Weiner JL, Dunwiddie TV, Valenzuela CF (1999) Ethanol inhibition of synaptically evoked kainate responses in rat hippocampal CA3 pyramidal neurons. Mol Pharmacol 56:85-90.

Woodward JJ (2000) Ethanol and NMDA receptor signaling. Crit Rev Neurobiol 14:69-89.

Wright JM, Peoples RW, Weight FF (1996) Single-channel and whole-cell analysis of ethanol inhibition of NMDA-activated currents in cultured mouse cortical and hippocampal neurons. Brain Res 738:249-256.

Zhu W, Pan ZZ (2004) Synaptic properties and postsynaptic opioid effects in rat central amygdala neurons. Neuroscience 127:871-879.

Zhu W, Pan ZZ (2005) Mu-opioid-mediated inhibition of glutamate synaptic transmission in rat central amygdala neurons. Neuroscience 133 97-103. 